\title{
Synthesis and characterization of highly ordered nanosized PbS thin films: modified silar
}

\author{
Kishorkumar V. Khot ${ }^{1, *}$, Vishvanth B. Ghanwat ${ }^{1}$, Pallavi B. Patil ${ }^{1}$, Chaitali S. Bagade ${ }^{1}$, Rahul M. Mane ${ }^{1}$, \\ Dadaso B. Shinde ${ }^{1}$, Sandip K. Jagadale ${ }^{1}$, Ji-hyung Jang ${ }^{2}$, P. N. Bhosale ${ }^{1, * *}$ \\ ${ }^{1}$ Materials Research Laboratory, Department of Chemistry, Shivaji University, Kolhapur, India \\ ${ }^{2}$ Nanocrystal Laboratory, School of Energy and Chemical engineering, Ulsan National Institute \\ of Science and Technology (UNIST), South Korea \\ *khotkishor7575@gmail.com, **p_n_bhosale@rediffmail.com
}

\section{PACS 81}

DOI 10.17586/2220-8054-2016-7-3-499-501

\begin{abstract}
In the current status, we have successfully synthesized lead sulfide (PbS) thin films using a modified successive ionic layer absorption and reaction (SILAR) method. The synthesized film was characterized using UV-Vis-NIR spectrophotometer, X-ray diffraction (XRD) and field emission scanning electron microscopy (FESEM) techniques for optical, structural and morphological properties. Opto-structural study demonstrates that synthesized thin film has a pure crystal structure. The surface morphology study indicates a nanospherical surface morphology without pinhole on the substrate surfaces. Overall study clearly demonstrates that the synthesized PbS thin film by SILAR method have great potential for sensitization of oxide microstructure.
\end{abstract}

Keywords: nanomaterials, thin films, SILAR method, XRD, SEM.

Received: 23 January 2016

Revised: 11 April 2016

\section{Introduction}

Lead sulfide $(\mathrm{PbS})$ belongs to the $\mathrm{IV}^{A}-\mathrm{VI}^{A}$ group of semiconductor materials. $\mathrm{PbS}$ is a black semiconductor with a band gap of $0.4 \mathrm{eV}$ (at $300 \mathrm{~K}$ ). It has great potential for fabrication of thin film solar cell due to its efficient light absorbing capacity from the visible to near infrared region of the solar spectrum, relatively long excitonic life time and the large excitation Bohr radius $(18 \mathrm{~nm})$, etc. Also, the band gap of $\mathrm{PbS}$ can be tuned from $0.41 \mathrm{eV}$ to $2.3 \mathrm{eV}$ by quantum size effect [1-4].

$\mathrm{PbS}$ thin films have potential utility in different applications, such as light emitting diodes, nonlinear optics, high speed switching, IR detectors, display devices, and solar cells. So far, both physical and chemical methods have been used to prepare $\mathrm{PbS}$ thin films. While, $\mathrm{PbS}$ thin films were synthesized by various methods, including vacuum evaporation, hot-wall epitaxy, molecular-beam epitaxy, pulsed laser deposition. These methods require sophisticated instrumentation and high cost, materials, etc. However, chemical methods mainly include spray pyrolysis, chemical bath deposition (CBD), successive ionic layer adsorption and reaction (SILAR), electrochemical deposition and hydrothermal method, etc [5].

In the present investigation, our main aim is to synthesize nanocrystalline $\mathrm{PbS}$ thin film, especially for the sensitization to hierarchically nanostructured metal oxide thin films such as, zinc oxide ( $\mathrm{ZnO}$ ) or titanium oxide $\left(\mathrm{TiO}_{2}\right)$ in order to improve the overall conversion efficiency. So considering this, we have selected SILAR technique, because compared to other techniques used, SILAR is best suited for development of sensitized solar cells. As well as, among these thin film synthesis techniques, SILAR has many superior properties such as simple application, low cost, low temperature synthesis and can be used to deposit the materials on a variety of substrates such as insulators, semiconductors, and metals. Therefore, we have synthesized PbS thin film on a soda lime glass substrate by using SILAR technique. Furthermore, the synthesized PbS thin film was characterized by using different techniques such as, UV-Vis-NIR spectrophotometer, X-ray diffraction (XRD) and field emission scanning electron microscopy (FESEM) for optical, structural and morphological studies respectively.

\section{Experimental details}

All chemicals in the experiment were purchased from Sigma Aldrich and without further purification. Lead nitrate $\left(\mathrm{Pb}\left(\mathrm{NO}_{3}\right)_{2}\right.$, Sigma Aldrich), sodium sulfide $\left(\mathrm{Na}_{2} \mathrm{~S}\right.$, Sigma Aldrich), methanol $\left(\mathrm{CH}_{3} \mathrm{OH}\right.$, Sigma Aldrich) were used for the synthesis of $\mathrm{PbS}$ thin film. In the $\mathrm{PbS}$ thin film synthesis, soda lime glass substrates were immersed in $0.1 \mathrm{M} \mathrm{Pb}\left(\mathrm{NO}_{3}\right)_{2}$ methanolic solution for 30 s to allow the absorption of $\mathrm{Pb}^{2+}$ ions and rinsed with a pure methanol solution for 1 min to remove loosely bound and excess $\mathrm{Pb}^{2+}$ ions. Then, substrates were dipped 
in $0.1 \mathrm{M} \mathrm{Na}_{2} \mathrm{~S}$ methanolic solution for 30 sec., where deposited $\mathrm{Pb}^{2+}$ ions react with $\mathrm{S}^{2-}$ ions to form a thin layer of $\mathrm{PbS}$ and rinsed with a pure methanol solution for $1 \mathrm{~min}$. These dipping procedures are called as "One SILAR cycle". In the present investigation, we have studied different properties of PbS thin film synthesized by 15 SILAR cycles. The synthesized PbS thin film is abbreviated as $\mathrm{PbS}$.

The film thickness was measured by using a surface profilometer (AMBIOS XP-1). An optical absorption study was carried out by using UV-Vis-NIR spectrophotometer (Shimadzu, UV-1800). The crystal structure of thin film was analyzed from X-ray diffraction study (XRD, D/MAX, Uitima III, Rigako Japan). The surface morphology was recorded from field emission scanning electron microscopy (FESEM, Hitachi, S4700).

\section{Results and discussions}

Thickness of synthesized PbS thin film is $70 \mathrm{~nm}$. The optical absorption spectrum of $\mathrm{PbS}$ thin film was recorded in the $400-2000 \mathrm{~nm}$ wavelength range and absorption plot is shown in Fig. 1(a). The optical absorption plot of the synthesized $\mathrm{PbS}$ thin film shows the linear nature of absorption.

Fig. 1(b) shows a direct band energy plot and the PbS thin film shows $1.40 \mathrm{eV}$ band gap energy value, which is in good accordance with other reported values in literature [6,7]. The crystal structure of the synthesized thin film was confirmed by using XRD study.

The Fig. 2 shows XRD pattern. PbS thin film shows diffraction peaks for (111), (200) and (220) planes at 25.70, 29.94 and $42.79^{\circ}$ respectively for cubic crystal structure (JCPDS Card No. 78-1058).

Figure 3 shows FESEM images of the PbS thin film deposited by SILAR method. The low resolution FESEM image indicates the formation of compactly arranged surface morphology with pinhole free nature (Fig. 3(a)). Further high resolution FESEM image of Fig. 3(b) clearly indicates that interconnected smaller nanospheres are grown on the substrate surface having an average grain size of about $30-40 \mathrm{~nm}$.
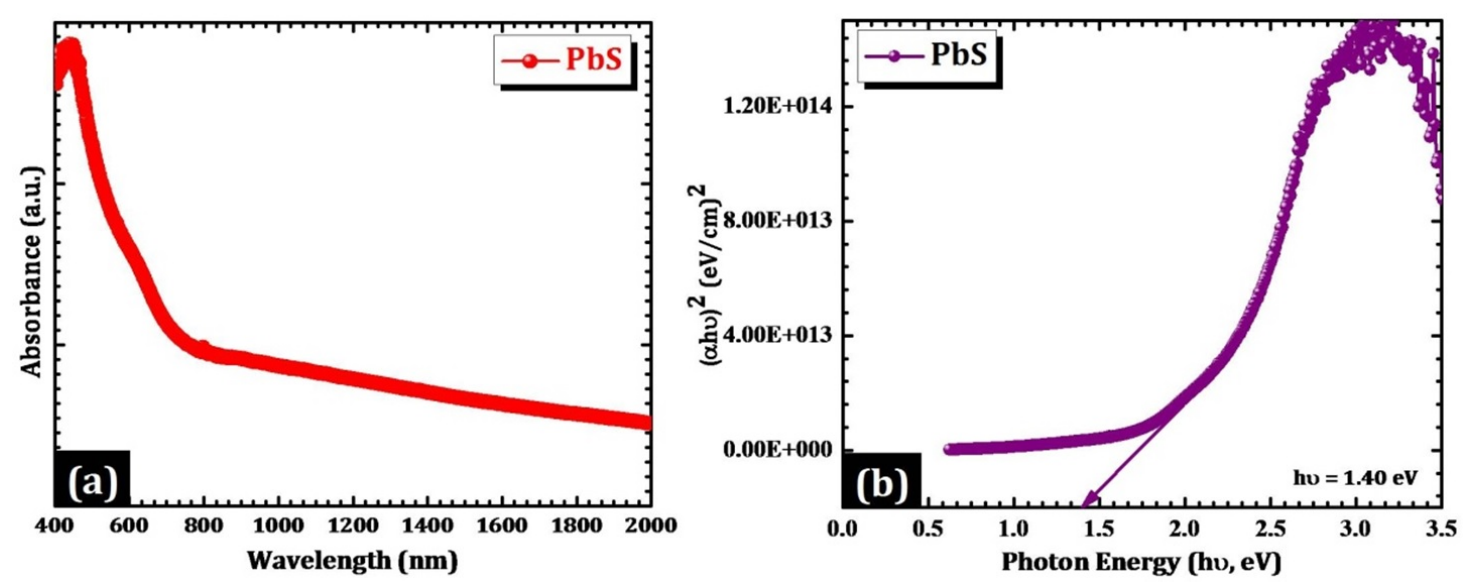

FIG. 1. (a) Optical absorption plot, (b) Plot of $\left(\alpha h \nu^{2}\right)(\mathrm{eV} / \mathrm{cm})^{2} v s$. photon energy (h $\left.\nu, \mathrm{eV}\right)$

\section{Conclusions}

In the present article, we have successfully synthesized a PbS thin film by using the modified SILAR method. The synthesized thin film shows directly allowed transition and a band gap energy of $1.40 \mathrm{eV}$. XRD pattern confirms the formation of cubic crystal structure. FESEM images demonstrated that interconnected smaller nanospheres are formed on the overall substrate surface with pinhole-free nature. The obtained results indicate that synthesized material is highly favorable for solar cell application.

\section{Acknowledgement}

One of the authors, Dr. Kishorkumar V. Khot is very much thankful to Department of Science and Technology (DST), New Delhi for awarding "DST-INSPIRE fellowship" for financial support (Registration No. IF130751). 


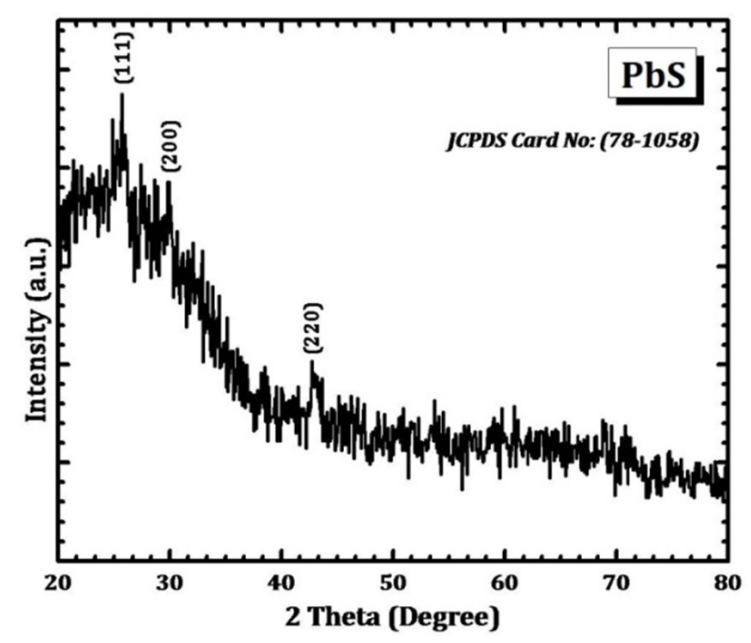

FIG. 2. XRD pattern of $\mathrm{PbS}$ thin film
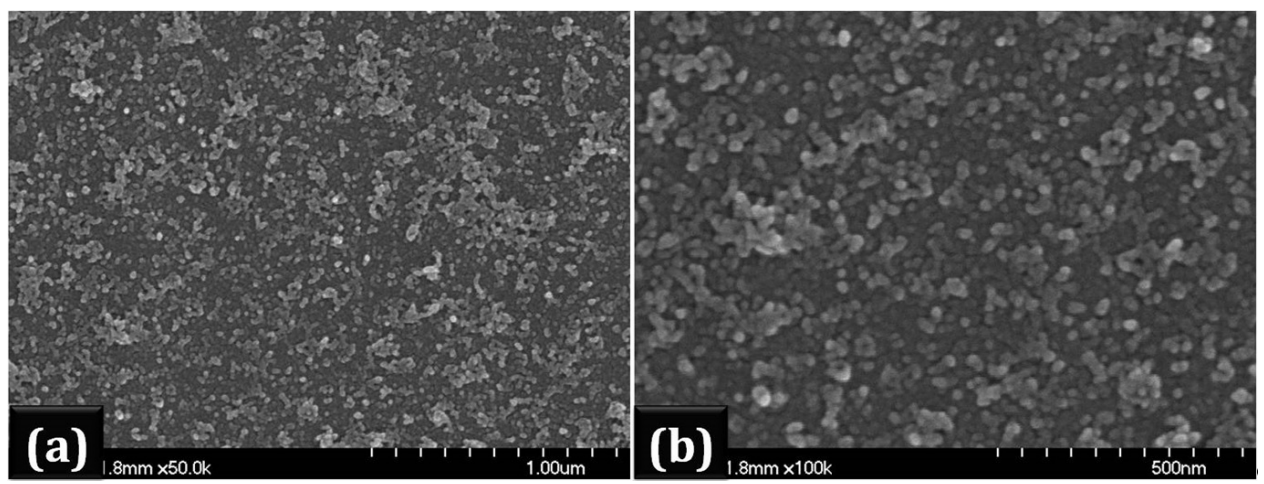

FIG. 3. (a,b) FESEM images of PbS thin film

\section{References}

[1] Mondal A., Mukherjee N. Cubic PbS thin films on TCO glass substrate by galvanic technique. Mater. Lett., 2006,60, P. $2672-2674$.

[2] Jauregui J.J.V., Bon R.R., Galvan A.M., Lerma M.S. Optical properties of PbS thin films chemically deposited at different temperatures. Thin Solid Films, 2003, 441, P. 104-110.

[3] Khot K.V., Mali S.S., Mane R.M., Patil P.S., Hong C.K., Kim J.H., Heo J., Bhosale P.N. Synthesis, characterization and photoelectrochemical properties of $\mathrm{PbS}$ sensitized vertically aligned $\mathrm{ZnO}$ nanorods: Modified aqueous route. J Mater Sci: Mater Electron, 2015, 26, P. 6897-6906.

[4] Saikia D., Phukan P. Fabrication and evaluation of CdS/PbS thin film solar cell by chemical bath deposition technique. Thin Solid Films, 2014, 562, P. 239.

[5] Khot K.V., Mali S.S., Ghanwat V.B., Kharade S.D., Mane R.M., Hong C.K., Bhosale P.N. Photocurrent enhancement in a Cu ${ }_{2}$ Cd(SSe) 2 photoanode synthesized via an arrested precipitation route. New. J. Chem., 2016, 40, P. 3277.

[6] Tohidi T., Ghaleh K.J., Namdar A., Ghaleh R.A. Comparative studies on the structural, morphological, optical, and electrical properties of nanocrystalline PbS thin films grown by chemical bath deposition using two different bath compositions. Mater. Sci.: Semicond. Process, 2014, 25, P. 197-206.

[7] Khot K.V., Mali S.S., Pawar N.B., Mane R.M., Kondalkar V.V., Ghanwat V.B., Patil P.S., Hong C.K., Kim J.H., He J.o, Bhosale P.N. Novel synthesis of interconnected nanocubic PbS thin films by facile aqueous chemical route. J. Mater. Sci.: Mater. Electron, 2014, 25, P. $3762-3770$. 